AperTO - Archivio Istituzionale Open Access dell'Università di Torino

\title{
Successful in vivo MRI tracking of MSCs labelled with Gadoteridol in a Spinal Cord Injury experimental model
}

\section{This is the author's manuscript}

Original Citation:

Availability:

This version is available http://hdl.handle.net/2318/1571912

since 2017-05-23T17:50:51Z

Published version:

DOI:10.1016/j.expneurol.2016.05.023

Terms of use:

Open Access

Anyone can freely access the full text of works made available as "Open Access". Works made available under a Creative Commons license can be used according to the terms and conditions of said license. Use of all other works requires consent of the right holder (author or publisher) if not exempted from copyright protection by the applicable law. 
This Accepted Author Manuscript (AAM) is copyrighted and published by Elsevier. It is posted here by agreement between Elsevier and the University of Turin. Changes resulting from the publishing process - such as editing, corrections, structural formatting, and other quality control mechanisms - may not be reflected in this version of the text. The definitive version of the text was subsequently published in EXPERIMENTAL NEUROLOGY, None (282), 2016, 10.1016/j.expneurol.2016.05.023.

You may download, copy and otherwise use the AAM for non-commercial purposes provided that your license is limited by the following restrictions:

(1) You may use this AAM for non-commercial purposes only under the terms of the CC-BY-NC-ND license.

(2) The integrity of the work and identification of the author, copyright owner, and publisher must be preserved in any copy.

(3) You must attribute this AAM in the following format: Creative Commons BY-NC-ND license (http://creativecommons.org/licenses/by-nc-nd/4.0/deed.en), 10.1016/j.expneurol.2016.05.023

The publisher's version is available at:

http://linkinghub.elsevier.com/retrieve/pii/S0014488616301418

When citing, please refer to the published version.

Link to this full text:

http://hdl.handle.net/2318/1571912 


\section{Accepted Manuscript}

Successful in vivo MRI tracking of MSCs labelled with Gadoteridol in a Spinal Cord Injury experimental model

Filippi Miriam, Boido Marina, Pasquino Chiara, Garello Francesca, Boffa Cinzia, Terreno Enzo

PII:

S0014-4886(16)30141-8

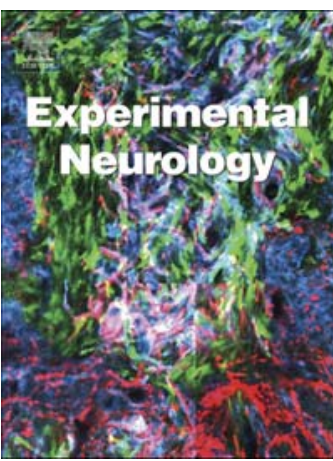

DOI:

doi: 10.1016/j.expneurol.2016.05.023

Reference:

YEXNR 12300

To appear in: $\quad$ Experimental Neurology

Received date: $\quad 26$ January 2016

Revised date: $\quad 26$ April 2016

Accepted date: 18 May 2016

Please cite this article as: Miriam, Filippi, Marina, Boido, Chiara, Pasquino, Francesca, Garello, Cinzia, Boffa, Enzo, Terreno, Successful in vivo MRI tracking of MSCs labelled with Gadoteridol in a Spinal Cord Injury experimental model, Experimental Neurology (2016), doi: 10.1016/j.expneurol.2016.05.023

This is a PDF file of an unedited manuscript that has been accepted for publication. As a service to our customers we are providing this early version of the manuscript. The manuscript will undergo copyediting, typesetting, and review of the resulting proof before it is published in its final form. Please note that during the production process errors may be discovered which could affect the content, and all legal disclaimers that apply to the journal pertain. 


\section{Successful in vivo MRI tracking of MSCs labelled}

\section{with Gadoteridol in a Spinal Cord Injury}

\section{experimental model.}

\section{Authors:}

Filippi Miriam $^{\mathrm{a} \#}$, Boido Marina ${ }^{\mathrm{b} \#}$, Pasquino Chiara ${ }^{\mathrm{c}}$, Garello Francesca ${ }^{\mathrm{a}}$, Boffa Cinzia ${ }^{\mathrm{a}}$, and Terreno Enzo ${ }^{\mathrm{a} *}$

\section{Affiliations:}

a Centro di Imaging Molecolare e Preclinico, Dipartimento di Biotecnologie Molecolari e Scienze della Salute, Università di Torino, Torino, 10126, Italia.

${ }^{b}$ Neuroscience Institute Cavalieri Ottolenghi, Department of Neuroscience, Università di Torino, Orbassano (Torino), 10043, Italia.

c Molecular Biotechnology Center, Dipartimento di Scienze Mediche, Università di Torino, Torino, 10126, Italia.

\section{Contact Information:}

* enzo.terreno@unito.it

\section{Additional Footnotes:}

"These two authors equally contribute to this article. 
Abstract: In this study, murine Mesenchymal Stem Cells (MSCs) labeled with the clinically approved MRI agent Gadoteridol through a procedure based on the hypo-osmotic shock were successfully tracked in vivo in a murine model of Spinal Cord Injury (SCI). With respect to isoosmotic incubations, the hypo-osmotic labeling significantly increased the $\mathrm{Gd}^{3+}$ cellular uptake, and enhanced both the longitudinal relaxivity $\left(r_{1}\right)$ of the intracellular Gadoteridol and the Signal to Noise Ratio (SNR) measured on cell pellets, without altering the biological and functional profile of cells. A substantial $\mathrm{T}_{1}$ contrast enhancement after local transplantation of $3.0 \times 10^{5}$ labeled cells in SCI mice enabled to follow their migratory dynamics in vivo for about 10 days, and treated animals recovered from the motor impairment caused by the injury, indicating unaltered therapeutic efficacy. Finally, analytical and histological data corroborated the imaging results, highlighting the opportunity to perform a precise and reliable monitoring of the cellbased therapy.

Keywords: Magnetic Resonance Imaging; Spinal Cord Injury; Cell Tracking; Hypotonic Swelling; Mesenchymal Stem Cell.

\section{Introduction}

Traumatic events as Spinal Cord Injury (SCI) often lead to permanent neurological deficits, resulting in loss of sensory and motor function below the injury level (Silva et al., 2014; Karimi et al., 2014). After the initial trauma, the formation of the glial cyst is accompanied by the activation and the recruitment of the immune cells (Dumont et al., 2001). The presence of the glial scar (McGraw et al., 2001) biologically and physically hinders axonal regeneration and functional recovery (Silver and Miller, 2004; Fawcett and Asher, 1999). Since the regrowth of CNS (Central Nervous System) severed axons is naturally limited, the spinal cord fibers may 
benefit from cell therapies promoting either circuit repair, or reorganization and axonal sprouting (Bowes and Yip, 2014). Specifically, stem cell (SC) transplantation strategies could represent a potential therapeutic approach in order to enhance cell/fiber rescue and functional recovery (Mortazavi et al., 2015), since (at least in animal models) they displayed a certain ability to differentiate into neural cells and replace lost populations, and to produce growth factors and anti-inflammatory cytokines enhancing the plasticity and supporting regenerative process (Garbossa et al., 2012). In particular, Mesenchymal SCs (MSCs) can exert a paracrine role, with positive significant effects on recovery (Schwab et al., 2002; Goldschlager et al., 2015).

Tracking cells in vivo by using imaging approaches represents a reliable method to assess the characteristics of cell grafts and to monitor their fate after transplantation (Aarntzen et al., 2012, Wang and Moore, 2012). In that respect, minimally invasive techniques with high spatial resolution are desirable with a view of implementing therapeutic protocols in the clinical ordinary (Spiriev et al., 2013). Magnetic Resonance Imaging (MRI) is a leading imaging modality enabling the non-invasive visualization of cell populations and their movements after transplantation in living animals with superb resolution (Bulte, 2009; Long and Bulte, 2009; Aghayan et al., 2014). In order to be detectable, cells require to be adequately labeled with MRI contrast agents (CAs) (Srivastava et al., 2015; Rogers et al., 2006). Due to their excellent imaging efficiency, the superparamagnetic iron oxide nanoparticles (SPIONs) are regarded as the gold standard in cell-labeling (Jendelová et al., 2004; Syková and Jendelová, 2005; Lepore et al., 2006; Zhang et al., 2013; Bach-Gansmo, 1993; Bull et al., 2014). However, some issues are associated to their contrast generation mechanism based on signal-loss (negative contrast) (BachGansmo, 1993). 
As a promising alternative, paramagnetic CAs based on the metal Gadolinium (Gd) create a contrast increment (positive contrast) in $\mathrm{T}_{1}$-weighted $\left(\mathrm{T}_{1 \mathrm{w}^{-}}\right)$images, overcoming several complications related to the use of SPIONs (Kraitchman et al., 2008; Shen et al., 2009). Even if toxic in the form of free aqueous ion, Gadolinium is generally considered safe when administered as a chelated compound and several agents have been approved for the clinical use so far. Differently from magnetic nanoparticles, large amounts of paramagnetic small molecules have to be delivered to target sites in order to be detected. Moreover, the process of cell internalization may reduce the CA efficiency by limiting its longitudinal relaxivity $\left(r_{1}\right)$ : it has been shown that upon entering the endocytic pathway, the enclosure into the endosomal membranes of the agent importantly restricts the exchange rate of water molecules on the paramagnetic center (Terreno et al., 2006; Gianolio et al., 2011).

Recently, a promising procedure for cell labeling with paramagnetic complexes was proposed, based on the 'hypo-osmotic shock' (Di Gregorio et al., 2013). Briefly, when the labeling incubation is performed into hypotonic media, the cell membrane becomes permeable, and the overall cell volume increases ('hypotonic swelling'). A water flow crosses the membrane bilayer, leading to a net income flux of small molecules present in the extracellular medium, such as the paramagnetic CAs. Because, in this way, CAs enter directly the cytoplasm, avoiding the endocytic vesicular transport chain, the 'quenching effect' on the $r_{1}$ caused by the inclusion into intracellular organelles is then mitigated (Terreno et al., 2006; Gianolio et al., 2011; Di Gregorio et al., 2013).

In the present study, we investigate the opportunity to efficiently label MSCs with the clinically approved positive agent Gadoteridol (Gd-HPDO3A) through the hypo-osmotic technique by comparing it with the correspondent labeling procedure performed into iso-osmotic environment. 
Given that the hypotonically labeled MSCs are administered as therapeutic agents to SCI mice, a deep description of their biologic profile, functional status and therapeutic efficacy is provided into detail. Finally, results from in vivo imaging are illustrated, highlighting the applicative potential of the procedure in visualizing transplanted cells and tracking their movements over time.

\section{Materials and Methods}

A full description of the experimental methods can be found in the section Supplemental Experimental Procedures of the Supplemental Information; a brief summary is given in the following.

Study design

The objective of this study was to assess the efficacy of the hypo-osmotic labeling in providing MSCs with MRI positive contrast, and to test both their imaging potential and their therapeutic performance after transplantation in vivo. For in vitro experiments, sample sizes were selected prior to initiating the study on the basis of initial setting experiments (that were not included in the analysis), and other data previously reported by the research group. Data collection was stopped when a smaller sample size achieved statistical significance. For in vivo experiments, SCI mice were divided in three groups: mice transplanted with MSCs labelled by iso-osmotic incubation (Iso-MSC), or by hypo-osmotic incubation (Hypo-MSC), or control mice injected with a correspondent volume of saline in the spinal cord (Sham Operated, SO). Unless otherwise indicated, 6 to 8 animals per group were randomly assigned to each study group. Injured mice causing self-mutilation were excluded from study. The experimentalists were not blinded to the identity of the groups while assaying the multiple aspects in this study. 


\section{Animal Care and Use}

All procedures involving live animals were performed according to European Community Council Directive of 24 November 1986 (86/609/EEC) and University of Turin's institutional guidelines on animal welfare (DL 116/92). C57BL/6J and Balb/c mice were used for the MSC extraction and SCI surgery, respectively. All animals were bred in the Center of Molecular Biotechnology (Torino, Italy), unless differently stated. In order to perform surgery and imaging, mice were anesthetized by intramuscular injection of a combination of tiletamine/zolazepam (Zoletil 100; Virbac, Milan, Italy) at $20 \mathrm{mg} / \mathrm{kg}$ and xylazine (Rompum; Bayer, Milan, Italy) at 5 $\mathrm{mg} / \mathrm{kg}$.

\section{Chemicals}

Gadoteridol (Gd-HPDO3A, marketed as ProHance ${ }^{\mathrm{TM}}$ ) was kindly provided by Bracco Imaging S.p.A. (Colleretto Giacosa, Torino, Italy). All materials necessary for cell culture [culture media, fetal bovine serum (FBS), trypsin and penicillin-streptomycin mixture] were purchased from Lonza (Lonza Sales AG, Verviers, Belgium), unless differently specified. All other chemicals were purchased from Sigma Chemical Co. (St Louis, MO, USA) and used as received.

\section{MSC culture and labeling}

MSCs were isolated from the bone marrow of male C57BL/6J mice (age: 7-9 weeks) weighting 22-28 g, as reported in the Supplementary Materials. MSCs were cultured in Minimal Essential Medium Eagle Alpha Modification, supplemented with penicillin (100 U/ml), streptomycin (100 $\mu \mathrm{g} / \mathrm{ml})$, FBS (10\%) and glutamine (2 mM), with medium renewal every 2-3 days. A highly efficient protocol for hypo-osmotic labeling was adopted (33): MSCs were maintained in suspension for 30 minutes at $37^{\circ} \mathrm{C}$ in a sterile saline Gadoteridol $(100 \mathrm{mM})$ solution with an overall osmolarity of $160 \mathrm{mOsm}^{-1}$. The external medium osmolarity was then restored by 
adding a proper amount of $300 \mathrm{mOsm} \mathrm{l}^{-1} \mathrm{PBS}$, and cells were allowed to recover their physiologic status for 30 minutes. Finally, not internalized Gadoteridol molecules were removed by extensive washes with PBS.

Cell viability, proliferation test and $G d^{3+}$ uptake test.

Cell viability and proliferation rate were estimated by using the Trypan Blue exclusion assay in 8 and 5 independent experiments respectively. A $0.4 \%$ solution of Trypan Blue in PBS (pH 7.2$7.3 ; 1: 1 \mathrm{v} / \mathrm{v}$ ) was added to harvested cells, before they were counted. The reported viability value and proliferation ability are expressed as: (i) the average ratio between the number of viable cells and the total number of cells $\left(\mathrm{N}_{\mathrm{v}} / \mathrm{N}_{\mathrm{t}} \times 100\right)$, and (ii) the ratio between the number of cells at each time point and the number of cells present at the beginning of the experiment $\left(\mathrm{N}_{\mathrm{t}} / \mathrm{N}_{0}\right)$. For $\mathrm{Gd}$ quantification, labeled cells were sonicated (Bandelin Sonopuls Sonicator, 20kHz, power 30\%, $30 \mathrm{~s}$ ), added with $1 \mathrm{ml}$ of concentrated $\mathrm{HNO}_{3}(70 \%)$ and completely digested by microwave heating (Milestone MicroSYNTH, Microwave labstation, Bergamo, Italy). Samples were suspended in ultrapure water and analyzed by Inductively Coupled Plasma Mass Spectrometry (ICP-MS, Thermo Scientific ELEMENT 2 ICP-MS -Finnigan, Rodano, Milano, Italy). Supernatant aliquots were treated as above indicated, but without applying the sonication.

\section{Evaluation of membrane resealing time}

The Methylene Blue dye (2.5 mM, for 5 minutes) was added to MSCs after different waiting times during the phase of the iso-osmolarity restoration which follows the hypotonic incubation. Stained cells were considered as owing a permeable membrane due to hypo-osmotic shock, and their percentage on the total population was reported.

Flow cytometry 
Cells were harvested, counted, divided into plastic tubes, resuspended with PBS supplemented with $0.1 \%$ Bovine Serum Albumin (BSA) and incubated with fluorochrome-conjugated monoclonal antibodies $(\mathrm{mAb})$ for $30 \mathrm{~min}$ at $4^{\circ} \mathrm{C}$. The following $\mathrm{mAbs}$ were used: anti-CD29(PE), anti-CD44-APC, anti-CD11b-FITC, anti-CD90-(PE) (BD Bioscience Pharmingen, San Jose, CA, USA), anti-Sca1-(PE) (Cedarlane, Burlington, Ontario, Canada), and anti-CD105-PE (MACS Milteny Biotec, San Diego, CA, USA). The fluorescence was quantitated on a FACSCalibur flow cytometer equipped with the CellQuest software (BD Biosciences).

\section{Cell differentiation}

Adipocytes and osteocytes were generated by culturing labeled cells in the adipogenic and osteogenic differentiation medium (Lonza, Biowhittaker, Belgium) respectively, with medium renewal performed each 2-3 days. Cell differentiation was then assessed by microscopic observation (DMI300B, Leica Microsystems, Nussloch, Germany) of cytoplasmic lipid droplets or calcium deposits (stained by Oil Red O and Alizarin Red, respectively).

\section{Cell pellet preparation and in vitro MRI}

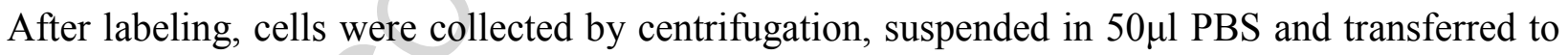
glass capillaries. Capillaries were centrifuged (5 minutes, $1500 \mathrm{rpm}$ ) and loaded onto an agar support for in vitro MRI. A Bruker Avance 300 spectrometer (Billerica, Massachusetts, USA) equipped with a micro-imaging probe was used to acquire images of capillaries on their axial section, at 7.1T. $\mathrm{T}_{1}$ values were measured by using a Saturation Recovery Spin Echo (SR-SE) sequence, while the percentage $T_{1}$ Contrast Enhancement $\left(T_{1}-C E\right)$ was calculated on the $T_{1 w^{-}}$ images. The mean Signal Intensity $\left(\mathrm{SI}_{0}\right)$ was calculated on ROIs manually drawn on the cell pellets and then normalized with respect to the signal produced by the external agarose support of the MRI phantom $\left(\mathrm{SI}_{\text {ref }}\right)$, in order to obtain the normalized Signal Intensity of labeled cell 
pellets, $\mathrm{SI}_{\mathrm{n} \text {-label }}$. The $\mathrm{T}_{1}$-CE was calculated with respect to the normalized signal measured for MSCs incubated with neat iso-osmotic or hypo-osmotic PBS $\left(\mathrm{SI}_{\mathrm{n} \text {-ctrl }}\right)$, by applying the following expression: $\mathrm{T}_{1}-\mathrm{CE}[\%]=\left(\mathrm{SI}_{\mathrm{n}-\mathrm{label}}-\mathrm{SI}_{\mathrm{n}-\mathrm{ctrl}}\right) / \mathrm{SI}_{\mathrm{n} \text {-ctrl }} \times 100$.

\section{SCI surgery and cell transplantation}

To induce acute SCI, male Balb/c mice (age: 10-12 weeks, weight: 27-30 g) were anesthetized, their lower thoracic and lumbar spinal cord was exposed, and its left side was hemisected at the level of the T13 vertebra (L2 neuromer) by using a 271/2-gauge needle. One week later, Iso- or Hypo-MSC-containing suspensions $\left(5.0 \times 10^{4}\right.$ cells/ $\left.\mu 1\right)$ or equivalent volumes of saline were injected into the white matter of the spinal cord by using a glass micropipette. 1.5 or $3.0 \times 10^{5}$ cells were injected for the experiments of cell graft visualization (see Fig. 3), whereas $3.0 \times 10^{5}$ cells were used to track the migration (see Fig. 4). The cell transplantation was performed one level caudal to the lesion (namely at L3 neuromer).

In vivo imaging

Anaesthesized animals were subjected to MRI scanning at $7.1 \mathrm{~T}$ (Bruker Avance 300 spectrometer) to assess the $\mathrm{T}_{1}$ contrast in the spinal cord by different acquisition geometries. The percentage $\mathrm{SNR}$ variation was calculated as follows: $\mathrm{SNR}[\%]=\left(\mathrm{SNR}_{\text {post }}-\mathrm{SNR}_{\mathrm{pre}}\right) / \mathrm{SNR}_{\text {pre }} \times$ 100 , where $\mathrm{SNR}_{\text {pre }}$ and $\mathrm{SNR}_{\text {post }}$ indicate the $\mathrm{SNR}$ calculated on the ROI before and after the transplantation, respectively. The SNR value was defined as the ratio between the Signal Intensity measured on the ROI $\left(\mathrm{SI}_{\mathrm{ROI}}\right)$ and the standard deviation of the background $\left(\sigma_{\mathrm{BG}}\right) . \mathrm{T}_{1 \mathrm{w}^{-}}$ images were acquired using a standard $\mathrm{T}_{1 \mathrm{w}}$-MSME (MultiSlice MultiEcho) sequence with the following parameters: $\mathrm{TR}=250 \mathrm{~ms}, \mathrm{TE}=4.7 \mathrm{~s}, \mathrm{FOV}=3.00 \times 3.00 \mathrm{~cm}$, matrix $=256 \times 256 \mathrm{pu}$, slice thickness $=1 \mathrm{~mm}$, average number $=10$, with a final space resolution of $0.12 \mathrm{~mm} / \mathrm{pu} . \mathrm{T}_{1}$ values were measured on sagittal images obtained by using a $\mathrm{T}_{1 \mathrm{w}}-\mathrm{MSME}$ sequence: $\mathrm{TE}=3.4 \mathrm{~ms}$, 10 variable 
TR ranging from 50 to $5000 \mathrm{~ms}, \mathrm{FOV}=3.00 \times 3.00 \mathrm{~cm}$, matrix $=128 \times 128 \mathrm{pu}$, slice thickness $=1 \mathrm{~mm}$. $\mathrm{T}_{2 \mathrm{w}}$-images endowed with high space resolution were used as anatomical references. Specifically, the anatomical images were acquired using a $T_{2 w}$-TurboRARE (Turbo Rapid Acquisition with Refocused Echoes) sequence set with the same acquisition geometry selected for the correspondent $\mathrm{T}_{1 \mathrm{w}}$-image, and with following parameters: $\mathrm{TR}=2500 \mathrm{~ms}, \mathrm{TE}=12.000 \mathrm{~ms}$, FOV $=3.00 \times 3.00 \mathrm{~cm}$, matrix $=384 \times 384 \mathrm{pu}$, slice thickness $=1 \mathrm{~mm}$, average number $=5$, RARE factor $=8$, with a final space resolution of $0.08 \mathrm{~mm} / \mathrm{pu}$.

Gd quantification in the spinal cord

After sacrifice (1, 7 or 10 days after Hypo-MSC transplantation), the vertebral column was removed and the spinal cord was divided into three regions (length: $\approx 3 \mathrm{~mm}$ ), including: the lesion site, the cell transplantation site, or the adjacent caudal region as a control area. The amount of $\mathrm{Gd}^{3+}$ was measured by ICP-MS and normalized to the weight of the excised tissue.

\section{Behavioural tests}

SCI mice underwent a series of behavioural tests to evaluate their motor recovery: the Basso Mouse Scale (BMS), the Paw Grip Endurance (PaGE), the foot-fault and the hindlimb flexion tests (Basso et al., 2006; Weydt et al., 2003; Pitsikas et al., 2001; Takamatsu et al., 2002). Prior to the SCI (day -7) and transplantation (day 0) surgery, animals were trained for the various tasks to determine the reference value range used as comparison with data collected after the administration of the cell-therapy.

\section{Histological examination and immunofluorescence}

For in vivo experiments, murine $\mathrm{GFP}^{+} \mathrm{MSCs}$ were used. Under anaesthesia, injured Hypo$\mathrm{GFP}^{+} \mathrm{MSC}$ mice were transcardially perfused with buffered 4\% PFA, $\mathrm{pH} 7.4$, before the T12-L3 vertebral segment of spinal cord was dissected. Samples were transferred into 30\% sucrose in 
$0.1 \mathrm{M}$ PB at $4{ }^{\circ} \mathrm{C}$ for cryoprotection, embedded in cryostat medium (Killik; Bio-Optica, Milan, Italy) and cut on the cryostat (Microm HM 550) in longitudinal $35 \mu \mathrm{m}$-thick sections. Before any further processing, all sections were mounted from PBS onto a slide, coverslipped and examined with a Nikon Eclipse E800 epifluorescence microscope, using an FITC-filter, in order to check the cell presence.

For immunofluorescence, the following antibodies were used: anti-GFP, anti-SMI32, anti-IBA1, and anti-GFAP. After washing in PBS, sections were incubated in cyanine-3- or cyanine-2conjugated anti-rabbit or anti-mouse secondary antibodies, as appropriate. The lesion, the transplantation site and the cell migratory flow were photographed by using the Coolpix digital camera.

\section{Statistical analysis}

All data were presented as Mean Values \pm Standard Deviation $(\mathrm{MV} \pm \mathrm{SD})$, unless noted otherwise. Significant differences among experimental conditions were identified by applying the unpaired Student's $t$-test, the repeated measures one-way or two-way ANOVA tests ( $p$-values $<0.05$ and 0.01 were marked as $*$ and $* *$ respectively).

\section{Results}

\section{Cell labeling and retention of the contrast agent}

Murine bone marrow-derived MSCs were labeled with Gadoteridol (Fig. 1A and B) by applying the labeling conditions demonstrating good performances in terms of cell safety and internalization efficiency (30 min, $160 \mathrm{mOsm} \mathrm{l}^{-1}, 37^{\circ} \mathrm{C}$ ) (Di Gregorio et al., 2013). The direct quantification of $\mathrm{Gd}$ in the cytoplasm (expressed as number of $\mathrm{Gd}^{3+}$ atoms per cell) revealed a significantly $(\approx 4$-fold) higher uptake of the CA in MSCs labeled by hypo-osmotic procedure 
(Hypo-MSCs) than in control cells undergoing the correspondent iso-osmotic incubation with Gadoteridol dissolved at the same concentration (Iso-MSCs, Fig. 1C). Even until 2 weeks after labeling, an evident difference in Gd content between the two labeling procedures was maintained, with Iso-MSCs almost completely losing their cargo about one week before HypoMSCs.

To deepen the evaluation concerning the fate and possible release of the $\mathrm{CA}$, the culture medium was also analyzed (Fig. 1D). Several days after labeling, a different content of Gd was found in the supernatants of equivalent numbers of Hypo-MSCs and Iso-MSCs: even though ISO-MSCs were assumed to have internalized lower initial CA amounts, their medium always displayed the higher concentration values. The peak in loss of ion content was reached after $48 \mathrm{~h}$ ( $2.9 \%$ for Hypo-MSCs vs. $18.6 \%$ for Iso-MSCs; ANOVA $p$-value < 0.05 ). Coherently to the hypothetical occurrence of release mechanisms, for both labeling procedures the metal concentration into the medium tended to increase in time. Based on the presented data, it is arguable that in the case of iso-osmotic uptake, easier and/or faster release processes are involved, possibly depending on the specific endosomal internalization route.

\section{In vitro $M R I$}

The MRI performance of the labeled cells was tested in vitro (Fig. 1E and F): on $\mathrm{T}_{1 \mathrm{w}}$-images, the pellets of Hypo-MSCs produced $\mathrm{a} \approx 2.6$-fold increased percentage in $\mathrm{T}_{1}$ Contrast Enhancement $\left(\mathrm{T}_{1}-\mathrm{CE}\right)$ with respect to the control incubation. As expected (Di Gregorio et al., 2013), the $r_{1}$ characterizing the Gadoteridol internalized by Hypo-MSCs $\left(3.70 \pm 0.55 \mathrm{mM}^{-1} \mathrm{~s}^{-1}\right)$ was found to be statistically higher $(t$-test $p$-value $<0.01)$ than the one calculated for Iso-MSCs $\left(1.88 \pm 0.29 \mathrm{mM}^{-1} \mathrm{~s}^{-1}\right)$, and more similar to the value of the free molecules in a simple water solution $\left(r_{1}=4.2 \pm 0.11 \mathrm{mM}^{-1} \mathrm{~s}^{-1}\right.$ in the same experimental condition, i.e. $0.5 \mathrm{~T}$ and $\left.25^{\circ} \mathrm{C}\right)$, thus 
indicating that the quenching effect of the relaxivity may occur, though at a much lower extent than the iso-osmotic labeling.

\section{Cell profile after labeling}

In order to prove the safety of the hypo-osmotic incubation, the biological profile of the labeled MSCs was tested in many aspects. First, cell viability resulted unaltered immediately, several hours or days after labeling (Fig. 2 A and S1), with a very low fraction of apoptotic cells in the population (Fig. S1). Second, no alteration of the proliferation ability was observed neither in Iso-MSCs nor in Hypo-MSCs, when compared to control unlabeled cells (Fig. 2B). Moreover, as Methylene Blue does not cross intact cell membranes, such cell staining was considered as a positive indicator of altered membrane permeability, enabling to estimate its resealing time (Fig. 2C). In fact, after the hypotonic incubation, a 'resealing phase' was carried out by restoring an external condition of iso-osmolarity: over longer resealing phases, the number of blue cells sensitively decreased (from $\approx 46 \%$ at $\mathrm{t}=0$, to $\approx 6 \%$ at $\mathrm{t}=20 \mathrm{~min}$ ) with a decay constant of $\approx 8$ minutes, indicating a fast recovery of the cell membrane physiological state. Finally, no evidence of alteration was found neither in the expression profile of surface markers (as MSC signature), nor in the differentiation potential of Hypo-MSCs (Fig. 2D, E, S2, S3, S4), suggesting that the labeling protocol could be suitable for safe in vivo translation.

In vivo imaging: visualization and tracking of grafted cells

For in vivo experiments, mice underwent the hemisection of the spinal cord at the level of the L2 neuromer, following the experimental outline shown in Fig. S5. Seven days after SCI, MSCs were transplanted caudally to the injury (at L3 level) in order to elicit the assessment of cell distribution and homing induced by the lesion. 
In a first set of experiments, a preliminary evaluation of the positive contrast generated by Isoand Hypo-MSC grafts was carried out onto $\mathrm{T}_{1 \mathrm{w}}$-images acquired with sagittal geometry. In mice receiving the cells, labeled MSCs were clearly discerned on $\mathrm{T}_{1 \mathrm{w}}$-images $24 \mathrm{~h}$ after the transplantation Fig. 3 and S6) and could be localized within a limited area $\left(\approx 1 \mathrm{~mm}^{2}\right)$ surrounding the injection site. Regions of interest (ROIs) corresponding to that specific area were drawn in order to calculate the percentage variation of the Signal to Noise Ratio (SNR) produced by a different number of transplanted cells: the SNR enhancement generated by Hypo-MSCs was $\approx 2.5$ and 2.1 -fold higher than that one determined by the Iso-MSCs when $1.5 \times 10^{5}$ or $3.0 \times 10^{5}$ cells were administered respectively (ANOVA $p$-values $<0.01$ and 0.05 ). Importantly, this experiment points out a significant in vivo efficacy, considering that in some reports, the MRI detection threshold in presence of optimal labeling conditions was found to be $2.5 \times 10^{5}$ and $5.0 \times 10^{5}$ cells for SPIONs and other Gd-complexes (i.e. Gd-DTPA) (Shen et al., 2009; Mathiasen et al., 2015).

In a second set of experiments, in vivo imaging was carried out for several days after the transplantation of $3.0 \times 10^{5}$ MSCs in order to verify whether the procedure could be useful in tracking cell migration. Indeed, MSCs are expected to move towards the injured tissue, attracted by the presence of lesion (Boido et al., 2009). Axial images were acquired along the longitudinal axes of the spinal cord, with the central image positioned onto the injection site ('slice 0 '), and other images covering equal distances in caudal and rostral directions, as illustrated in Fig. 4A. The SNR values in each slice were calculated 1, 3, 5, 7, and 10 days after transplantation, and then graphed as time and position-dependent variations of the contrast (Fig. 4B, C, D, E, F). At day 1, both Iso- and Hypo-MSCs-transplanted mice showed a SNR peak in the central slice, reflecting the highly circumscribed signal arising from the cell graft. The difference in the SNR 
enhancement calculated between the two groups confirmed the data acquired in previous experiments. In the following days, high SNR values were calculated in rostral slices, but not in caudal slices, thus suggesting that cell movements mobilizing the contrast source occur in direction of the target lesion. Importantly, for Hypo-MSCs the acquisition of significant SNR values reached and did not exceed the imaging slice containing the injury, with the $T_{1}$ signal progressively fading in time, and becoming weak and diffused at day 10 . On the contrary, the Iso-MSC signal appeared as considerably decreased by day 5 and almost exhausted by day 7 . At day 10, the SNR enhancement generated in proximity of the lesion ('slice 3') in the Hypo-MSCsmice was limited $(\approx 10.14 \% \pm 6.16)$ but still significantly higher than that observed in Iso-MSCsmice $(\approx 1.09 \% \pm 2.63$, ANOVA $p$-value $<0.05)$. Furthermore, in control experiments performed in the absence of lesion, no cell movements have been detected, confirming that homing is only triggered by lesion (Fig. S7). Coherently, $\mathrm{T}_{1}$ values calculated by $\mathrm{T}_{1}$-measurement $\mathrm{MR}$ sequences in the same spinal cord regions were in good accordance with the $\mathrm{T}_{1 \mathrm{w}}$-imaging data (Fig. 4G), thus confirming that the source of the increased signal intensities corresponded to the Gd-dependent effects on the $\mathrm{T}_{1}$ relaxation time, and other artifacts or disturbances in the signal could be excluded. Importantly, at day 1 the Hypo-MSCs grafts induced a $\mathrm{T}_{1}$ decrease of $\approx 33.9 \%$ and $0.7 \%$ in the sites of transplantation and lesion, respectively, with respect to the average endogenous $T_{1}$ value of the spinal cord tissue $(1671.9 \pm 32.9 \mathrm{~ms}$, Fig. 4G). At day 7, a mild but still distinguishable effect was present, determining a similar $T_{1}$ decrease in the two regions $(\approx 9.43 \%$ and $5.6 \%$ in the transplantation and lesion site, respectively). Finally, the tissue distribution of Gd in Hypo-MSCs-animals quantitatively supported the imaging results at some extent (Fig. 4H): a considerable metal content was found at day 1 in the spinal cord portion $(\approx 3 \mathrm{~mm}$ in length $)$ in proximity of the transplantation site. At day 7 , the amounts of Gd measured 
in the transplantation and the lesion-portion were almost equivalent, but statistically higher than that found in the caudal region (ANOVA $p$-value $<0.05$ ). At day 10, no relevant Gd traces were detected in none of the considered regions. Representative $\mathrm{T}_{1 \mathrm{w}}$-images collected during the cell tracking experiments are reported in Fig. $\mathbf{5}$ and S8, and highlight the visual differences that can be obtained on the axial geometry of the spinal cord.

\section{Therapeutic effects}

To verify whether the labeling procedure could alter the therapeutic efficacy of MSCs, behavioural studies were carried out on the three groups of SCI animals that respectively received 3.0 $\times 10^{5}$ Iso- or Hypo-MSCs in $6 \mu 1$ of saline, or an equivalent volume of saline (Sham Operated, SO; Fig. 6). The tests were designed to evaluate the motor recovery (Basso et al., 2006; Weydt et al., 2003; Pitsikas et al., 2001; Takamatsu et al., 2002) until 40 days after transplantation (performed at day 0 , one week after the hemisection surgery). Few days after MSC or saline injection, a slight and expected spontaneous recovery was observed in all groups. During the first week of monitoring, the behavioural outcome in all tests was very variable, so that no evident differences were noticed among the cohorts. Nevertheless, while untreated animals continued to obtain similar scores during the following weeks, the performances of celltransplanted mice were associated to a significant positive outcome, without any relevant difference between Iso- or Hypo-MSCs.

In all injured animals, evident trunk instability, abnormal posture but extensive ankle movements were present before cell transplantation (Fig. 6A). The injection (cells/saline) at day 0 possibly caused an initial transitory worsening of the locomotor conditions, further reducing the ankle motility for few days. However, 10 days after graft/saline, only transplanted mice obtained increasing BMS scores, culminating in values at day 40 that were statistically higher than those 
obtained by the control mice (ANOVA $p$-value $<0.05$ ), and indicate frequent plantar stepping with a certain degree of coordination $(6.00 \pm 1.00,5.33 \pm 0.58$ and $3.33 \pm 0.58$ for Iso-, Hypo-MSC and SO mice, respectively).

In the foot-fault test (Weydt et al., 2003), Iso- and Hypo-MSCs-mice performed $6.67 \pm 1.15$ and $6.67 \pm 0.58$ foot-faults at the day they were sacrificed, improving their ability to execute a correct stepping by $41.19 \%$ and $42.85 \%$ with respect to day 0 (vs. $21.07 \%$-improvement achieved by SO mice, Fig. 6B). Statistical relevance was documented only when the foot-fault scores (day 40) of transplanted mice were compared to those of the untreated ones (ANOVA $p$-value $<0.05$ and 0.01 for Iso- and Hypo-MSC mice, respectively).

The Paw Grip Endurance (PaGE) test was used to assess the resistance force of the injured hindlimb (Pitsikas et al., 2001). At day 0, the resistance time was similar among all mice (average time $\approx 55.83 \pm 1.93 \mathrm{~s}$, Fig. $6 \mathrm{C}$ ). Even though a full recovery was never observed, at day 40 both transplanted groups displayed a greater performance outcome $(65.3 \pm 4.36 \mathrm{~s}$ and $72.9 \pm 9.26 \mathrm{~s}$ for Iso- and Hypo-MSC mice, respectively) compared to SO mice $(54.07 \pm 1.76 \mathrm{~s}$, ANOVA $p$-value $<0.05$ ).

The last test (Fig.6D) provided a general assessment of the flexion movement and the retractile force of the damaged hindlimb (score 3 refers to maximum hindlimb impairment, and score 0 to the physiological condition) (Takamatsu et al., 2002). At the end of monitoring, both Iso- and Hypo-MSC-transplanted groups displayed $\approx 4.15$-fold decreased scores, reflecting better therapeutic outcomes (ANOVA $p$-value $<0.05)$ in comparison to untreated mice $(\approx 1.15$-fold decreased score).

Histological examination 
In order to gain deeper insights at a cellular level, immunofluorescence was carried out on animals treated with Hypo-GFP ${ }^{+}$-MSCs. The coronal $\mathrm{T}_{1 \mathrm{w}}$-imaging (Fig. 7A) acquired 7 days after the transplantation illustrates the positive contrast generated by cells that appeared as diffused along a migratory stream extending between the injection and the lesion site. $T_{2 w^{-}}$ imaging, used as anatomical reference, could provide a clear representation of the lesion. The GFP immunofluorescence on the spinal cord of the same animal revealed a similar cell distribution, suggesting the co-localization of the MSCs with the MRI-responsive agent (Fig. 7B). The stream extension measured on the $\mathrm{T}_{1 \mathrm{w}}$-image $(\approx 2.9 \mathrm{~mm})$ was consistent with the size observed in the microscopic images. Both at the transplantation and lesion sites, $\mathrm{IBA}^{+}$microglial cells (Fig. 7C and D) and GFAP ${ }^{+}$astrocytes (Fig. 7E and F) were detected, suggesting that neuroinflammatory events were ongoing, even though to a moderate extent. Moreover, Fig. 7E clearly shows the glial scar surrounding the glial cyst (empty of astrocytes) at the hemisection site. Distribution and morphology of hypo-GFP+-MSCs are visible in Fig. 7G-I. 7 days after graft, a remarkable number of cells survived and integrated into the host tissue. Concerning the morphology, cells either showed fibroblast-like shape (Fig. 7G) or appeared elongated (Fig. 7HI). Similarly, Fig. 7J-M displays $\mathrm{GFP}^{+}$cells lined up following the SMI32-positive fibers orientation, indicating that the elongated MSC shape reflected their arrangement along the axons and that transplantation was actually performed inside the spinal cord white matter: this means that extensive cell dispersion in the liquor of the central canal did not occur. Taken together, these observations confirm the MRI results and show the ability of Hypo-GFP ${ }^{+}$-MSCs to survive and integrate into the spinal cord, as previously demonstrated with unlabelled cells (Boido et al., 2009). 


\section{Discussion}

The visualization of grafted cells represents an appealing objective to pursue in the cell-based regenerative treatment of SCI, where SCs play an active role in providing a positive therapeutic outcome (Bowes and Yip, 2014; Mortazavi et al., 2015; Garbossa et al. 2012; Schwab, 2002). So far, the SPIONs have been extensively exploited for MRI tracking of therapeutic cells in the SCI, showing excellent imaging efficiency (Jendelová et al., 2004; Syková and Jendelová, 2005; Lepore et al., 2006; Zhang et al., 2013). However, on $\mathrm{T}_{2}$ - and $\mathrm{T}_{2}{ }^{*}$-weighted MRI $\left(\mathrm{T}_{2 \mathrm{w}^{-}}\right.$and $\mathrm{T}_{2 \mathrm{w}}{ }^{*}-$ MRI), SPIONs appear as hypointense regions, namely signal voids producing a negative contrast (Bach-Gansmo, 1993), thus making arduous the detection of the labeled cells into anatomic areas endowed with low intrinsic MRI signal. After surgery, tissues frequently display low signal intensities due to hemorrhage and micro air bubbles deposition. As a consequence, it proves challenging to state whether the intracellular SPIONs are the real source of the observed negative contrast. In the therapeutic protocols requiring local cell transplantation, this aspect has to be seriously taken into account, considering that, in the absence of specific cell vehicles (such as hydrogels), the injection procedure is expected to create empty spaces and introduce air into tissue along the needle path (Bull, 2014). Furthermore, arising from indirect microscopic disturbances of the magnetic field, the SPION signal can be hardly correlated to the number of grafted cells (Bach-Gansmo, 1993; Bull, 2014), and is frequently affected by blooming artifacts, causing a diffuse darkening that may lead to incorrect assessment of the colony size or position (Bach-Gansmo, 1993; Bull, 2014; Bulte, et al., 2001). Finally, besides unclear cytotoxic phenomena, SPIONs interact with the static magnetic field and are responsible for abnormal distribution of iron filled-endosomes (Crichton et al., 2002; Wilhelm et al., 2003). 
The rationale of the present study was conceived in the effort to overcome these complications by labeling cells with positive CAs, although, as small molecules, they can hardly compete with the particle-based negative labeling in terms of efficiency. Some first efforts to track SCs in SCI by positive MRI CAs have been previously done in rats by using chemical transfection agents to increase the labeling efficacy of Gd-DTPA, a positive agent endowed with a linear chelating cage (Shen et al., 2009). In the present report, we proposed the safe technique of the hypotonic swelling to optimize the cell imaging performance in murine models. Due to the osmotic shock that eukaryotic cells experience when they are suspended into a hypo-osmotic solution, the cell membrane permeability to small molecules is expected to increase, and large amounts of the CA can be internalized following the concentration gradient. At the end of the process, the normal cell morphology can be recovered by simply restoring the iso-osmotic condition of the extracellular medium. The clinically approved $\mathrm{T}_{1} \mathrm{CA}$ Gadoteridol was chosen among the MRI detectable agents to maximize the safety, and thus the clinical translatability of the procedure. In fact, since the chelating carrier of $\mathrm{Gd}(\mathrm{III})$ is endowed with a macrocyclic geometry, Gadoteridol is provided with a higher thermodynamic and kinetic stability with respect to other Gd-based CAs with linear architecture (Runge et al., 1994). Moreover, being small-sized, hydrophilic, neutral, and normally well tolerated by cells even at high dosages (Ferrauto et al., 2013), it is already involved in a wide spectrum of medical imaging applications, particularly in the study of the CNS (Runge et al., 1994).

Altogether, our results provide evidence that, with respect to standard techniques, the hypotonic labeling generates a boosted positive contrast enhancement in vitro with increased $r_{1}$ of the intracellular Gadoteridol and higher internalization rate, without any negative consequences on the viability, biological profile or functional potential of the MSCs both in vitro and in vivo. The 
transplantation site of Hypo-MSCs and their local distribution immediately after the transplantation can be circumscribed, such that the cell engraftment can be contoured with precision and its size can be estimated. Also, the higher signal intensity and the longer monitoring time allowed to trace and measure the entire migration pathway leading the cells from the transplantation to the lesion site, suggesting a potential utility in defining the cell movements in response to biologic stimuli within experimental contexts (for instance, to study the chemotactic recruitment). Finally, the analytical and histological validation data describing the distribution of the $\mathrm{CA}$ and cells corroborated the reliability of the labeling and imaging protocols.

Even though promising results were obtained, it has to be noticed that the labeled cells cannot be imaged in vivo for competitive time ranges with SPIONs, which can be visualized for several weeks (Jendelová et al., 2004; Syková and Jendelová, 2005; Lepore et al., 2006; Zhang et al., 2013; Bach-Gansmo, 1993; Bull et al., 2014). In fact, the movements of transplanted HypoMSCs labeled with Gadoteridol could not be monitored for more than 10 days. However, in contrast to iron oxides, metabolic pathways for intra-cytoplasmic Gd-chelates have not been described yet (Giesel et al., 2006), so that they are generally regarded as inert long-term species. The progressive diminishing of the contrast could be ascribed to ongoing cell divisions (Walczak et al., 2007) and diffused spreading into tissue. Furthermore, another limitation in the reported procedure consists in the possibility that the signal detected by MRI arouse from phagocytosed or dead transplanted cells. Nevertheless, considering that (i) a rapid wash out for Gd-chelates in dead cells or interstitial spaces was already reported (Ludemann et al., 2002), (ii) our histological analysis did not show any dying cells, and (iii) the in vivo efficacy of the cell-therapy in improving the motor dysfunctions was proved, we hypothesize that the possibility of having 
imaged consistent populations of dead or phagocytosed cells in the spinal cord was low. Finally, although it is evident that the extent of glial scarring and the relative pathogenetic mechanisms are different when compared to human subjects (Hook et al., 2013), and preclinical evaluations in larger animal models (such as dogs, pigs and nonhuman primates) (Freidli et al., 2015) are necessary, the rodents still represent the most commonly employed species for preliminary SCI studies, Here, we employed a murine experimental model of SCI, whose advantages are mainly related to: (i) the high reproducibility of the trauma; (ii) the possibility to compare the results worldwide thanks to standardized behavioural, histological, biochemical and molecular techniques; (iii) the limited cost of housing facilities (Zhang et al., 2014). The statistically significant differences between Hypo- and Iso-labeling indicate that the Hypo-labeling can be practically helpful for imaging-guided monitoring of cell transplantation in mice, but they could be potentially valid also in larger animals and humans. From a preclinical point of view, the Hypo-labeling could be exploited to test and compare different methods of transplantation, to dynamically assess the beneficial effects of cell graft relating the behavioural data to the MRI observations, or to analyze the ability of the injected cells to move towards the lesion site or even to enter into the glial cyst in real-time. Finally, the opportunity to follow the same injected animal during time can significantly reduce the total number of mice sacrificed at different time points. Due to the limited persistence of the contrast, from a translational point of view, the presented technique could provide basic information on the cell graft survival in the first days after injection: indeed, it is reported that the possible detrimental response of the host CNS to the graft can be very fast and transplanted cells can die within the first hours after transplantation (De Vocht et al., 2013). 


\section{Conclusions}

The low invasiveness, the superb spatial resolution, the lack of radiation and the ability to anatomically characterize the SCI pathology (Miyanji et al., 2007), make of MRI the first choice to design new clinically translatable imaging protocols (Walczak and Bulte, 2007). In a time when increasing research efforts are directed to the detailed definition of the cell biology after transplantation, we believe that an efficient, safe and simple labeling technique may open up new prospects towards the major practical medical needs, such as the dynamic evaluation of the celltherapy over longer duration, with higher efficacy and substantial reliability of acquired information. Hopefully, the hypo-osmotic labeling will be helpful in addressing the current challenges imposed in the neurotransplantation field by the complexity of the CNS and the specific medical requirements of stem cell-based therapy (Walczak and Bulte, 2007).

Author contributions: M. F. designed the study, performed experiments and data analysis, and wrote the paper. M. B. designed and performed experiments, and edited the paper. C. P., F. G., and C. B. performed experiments. E. T. conceived the idea, provided funding, and edited the paper.

Acknowledgments: We thank F. T. Bianchi and C. Tocco for technical assistance, and L. Tei for graphical support. This work has been partially funded by the EU-FP7 project INMiND (Imaging neuroinflammation in neurodegenative diseases), grant number 278850. The authors declare that they have no competing interests.

\section{References:}

1. Silva, N.A., Sousa, N., Reis, R.L., and Salgado, A.J., 2014. From basics to clinical: a comprehensive review on spinal cord injury. Prog. Neurobiol. 114, 25-57. 
2. Karimi, M., Omar, A.H., and Fatoye, F., 2014. Spinal cord injury rehabilitation: which way forward?. NeuroRehabilitation. 35, 325-40.

3. Dumont, R.J., Okonkwo, D.O., Verma, S., Hurlbert, R.J., Boulos, P.T., Ellegala, D.B., and Dumont, A.S., 2001. Acute spinal cord injury, part I: pathophysiologic mechanisms. Clin. Neuropharmacol. 24, 254-264.

4. McGraw, J., Hiebert, G.W., and Steeves, J.D., 2001. Modulating astrogliosis after neurotrauma. J. Neurosci. Res. 63, 109-115.

5. Silver, J., and Miller, J.H., 2004. Regeneration beyond the glial scar. Nat. Rev. Neurosci. $5,146-56$.

6. Fawcett, J.W., and Asher, R.A., 1999. The glial scar and central nervous system repair. Brain Res. Bull. 49, 377-391.

7. Bowes, A.L., and Yip, P.K., 2014. Modulating inflammatory cell responses to spinal cord injury: all in good time. J. Neurotrauma. 31, 1753-66.

8. Mortazavi, M.M., Harmon, O.A., Adeeb, N., Deep, A., and Tubbs, R.S., 2015. Treatment of spinal cord injury: a review of engineering using neural and mesenchymal stem cells. Clin. Anat. 28, 37-44.

9. Garbossa, D., Boido, M., Fontanella, M., Fronda, C., Ducati, A., and Vercelli, A., 2012. Recent therapeutic strategies for spinal cord injury treatment: possible role of stem cells. Neurosurg. Rev. 35, 293-311.

10. Schwab, M.E., 2002. Repairing the injured spinal cord. Science 295, 1029-1031.

11. Goldschlager, T., Oehme, D., Ghosh, P., Zannettino, A., Rosenfeld, J.V., and Jenkin, G., 2015. Current and future applications for stem cell therapies in spine surgery. Curr. Stem. Cell. Res. Ther. 8, 381-93. 
12. Aarntzen, E.H., Srinivas, M., Walczak, P., Janowski, M., Heerschap, A., de Vries, I.J., Figdor, C.G., Bulte, J.W., and Oyen, W.J., 2012. In vivo tracking techniques for cellular regeneration, replacement, and redirection. J. Nucl. Med. 53, 1825-8.

13. Wang, P., and Moore, A., 2012. Molecular imaging of stem cell transplantation for neurodegenerative diseases. Curr. Pharm. Des. 18, 4426-40.

14. Spiriev, T., Sandu, N., and Schaller, B., 2013. Molecular imaging and tracking stem cells in neurosciences. Methods Mol. Biol. 1052, 195-201.

15. Bulte, J.W., 2009. In vivo MRI cell tracking: clinical studies. Am. J. Roentgenol. 193, 314325.

16. Long, C.M., and Bulte, J.W., 2009. In vivo tracking of cellular therapeutics using magnetic resonance imaging. Expert. Opin. Biol. Ther. 9, 293-306.

17. Aghayan, H.R., Soleimani, M., Goodarzi, P., Norouzi-Javidan, A., Emami-Razavi, S.H., Larijani, B., and Arjmand, B., 2014. Magnetic resonance imaging of transplanted stem cell fate in stroke. J. Res. Med. Sci. 19, 465-471.

18. Srivastava, A.K., Kadayakkara, D.K., Bar-Shir, A., Gilad, A.A., McMahon, M.T., and Bulte J.W., 2015. Advances in using MRI probes and sensors for in vivo cell tracking as applied to regenerative medicine. Dis. Model. Mech. 8, 323-336.

19. Rogers, W.J., Meyer, C.H., and Kramer, C.M., 2006. Technology insight: in vivo cell tracking by use of MRI, Nat. Clin. Pract. Cardiovasc. Med. 3, 554-562.

20. Jendelová, P., Herynek, V., Urdzíková, L., Glogarová, K., Kroupová, J., Andersson, B., Bryja, V., Burian, M., Hájek, M., and Syková, E., 2004. Magnetic resonance tracking of transplanted bone marrow and embryonic stem cells labeled by iron oxide nanoparticles in rat brain and spinal cord. J. Neurosci. Res. 76, 232-243. 
21. Syková, E., and Jendelová, P., 2005. Magnetic resonance tracking of implanted adult and embryonic stem cells in injured brain and spinal cord. Ann. N. Y. Acad. Sci. 1049, 146160.

22. Lepore, A.C., Walczak, P., Rao, M.S., Fischer, I., and Bulte, J.W., 2006. MR imaging of lineage-restricted neural precursors following transplantation into the adult spinal cord. Exp. Neurol. 201, 49-59.

23. Zhang, R., Zhang, K., Li, J., Liu, Q., and Xie, J., 2013. In vivo tracking of neuronal-like cells by magnetic resonance in rabbit models of spinal cord injury. Neural. Regen. Res. 8 , $3373-3381$.

24. Bach-Gansmo, T., 1993. Ferrimagnetic susceptibility contrast agents. Acta Radiol. Suppl. $387,1-30$.

25. Bull, E., Madani, S.Y., Sheth, R., Seifalian, A., Green, M., and Seifalian, A.M., 2014. Stem cell tracking using iron oxide nanoparticles. Int. J. Nanomedicine. 9, 1641-1653.

26. Kraitchman, D.L., Gilson, W.D., and Lorenz, C.H., 2008. Stem cell therapy: MRI guidance and monitoring. J. Magn. Reson. Imaging. 27, 299-310.

27. Shen, J., Zhong, X.M., Duan, X.H., Cheng, L.N., Hong, G.B., Bi, X.B., and Liu, Y., 2009. Magnetic resonance imaging of mesenchymal stem cells labeled with dual (MR and fluorescence) agents in rat spinal cord injury. Acad. Radiol. 16, 1142-1154.

28. Terreno, E., Geninatti Crich, S., Belfiore, S., Biancone, L., Cabella, C., Esposito, G., Manazza, A.D., and Aime, S., 2006. Effect of the intracellular localization of a Gd-based imaging probe on the relaxation enhancement of water protons, Magn. Reson. Med. 55, 491-497. 
29. Gianolio, E., Arena, F., Strijkers, G.J., Nicolay, K., Högset, A., and Aime, S., 2011. Photochemical activation of endosomal escape of MRI-Gd-agents in tumor cells. Magn. Reson. Med. 65, 212-219.

30. Di Gregorio, E., Ferrauto, G., Gianolio, E., and Aime, S., 2013. Gd loading by hypotonic swelling: an efficient and safe route for cellular labeling. Contrast Media Mol. Imaging 8, 475-86.

31. Basso, D.M., Fisher, L.C., Anderson, A.J., Jakeman, L.B., McTigue, D.M., Popovich, P.G., 2006. Basso Mouse Scale for locomotion detects differences in recovery after spinal cord injury in five common mouse strains. J. Neurotrauma. 23, 635-59.

32. Weydt, P., Hong, S.Y., Kliot, M., and Möller, T., 2003. Assessing disease onset and progression in the SOD1 mouse model of ALS. Neuroreport. 14, 1051-1054.

33. Pitsikas, N., Brambilla, A., Besozzi, C., Bonali, P., Fodritto, F., Grippa, N., Scandroglio, A., and Borsini, F., 2001. Effects of cerestat and NBQX on functional and morphological outcomes in rat focal cerebral ischemia. Pharmacol. Biochem. Behav. 68, 443-447.

34. Takamatsu, H., Tatsumi, M., Nitta, S., Ichise, R., Muramatsu, K., Iida, M., Nishimura, S., and Umemura, K., 2002. Time courses of progress to the chronic stage of middle cerebral artery occlusion models in rats. Exp. Brain Res. 146, 95-102.

35. Mathiasen, A.B., Hansen, L., Friis, T., Thomsen, C., Bhakoo, K., and Kastrup, J., 2013. Optimal labeling dose, labeling time, and magnetic resonance imaging detection limits of ultrasmall superparamagnetic iron-oxide nanoparticle labeled mesenchymal stromal cells. Stem Cells Int. 2013, 353105. 
36. Boido, M., Rupa, R., Garbossa, D., Fontanella, M., Ducati, A., and Vercelli A., 2009. Embryonic and adult stem cells promote raphespinal axon outgrowth and improve functional outcome following spinal hemisection in mice. Eur. J. Neurosci. 30, 833-846.

37. Bulte, J.W., Douglas, T., Witwer, B., Zhang, S.C., Strable, E., Lewis, B.K., Zywicke, H., Miller, B., van Gelderen, P.B., Moskowitz, M., Duncan, I.D., and Frank, J.A., 2001. Magnetodendrimers allow endosomal magnetic labeling and in vivo tracking of stem cells. Nat. Biotechnol. 19, 1141-1147.

38. Crichton, R.R., Wilmet, S., Legssyer, R., and Ward, R.J., 2002. Molecular and cellular mechanisms of iron homeostasis and toxicity in mammalian cells. J. Inorg. Biochem. 91, $9-18$.

39. Wilhelm, C., Cebers, A., Bacri, J.C., Gazeau, F., 2003. Deformation of intracellular endosomes under a magnetic field. Eur. Biophys. J. 32, 655-660.

40. Ferrauto, G., Delli Castelli, D., Terreno, E., and Aime, S., 2013. In vivo MRI visualization of different cell populations labeled with PARACEST agents. Magn. Reson. Med. 69, 1703-1711.

41. Runge, V.M., Kirsch, J.E., Wells, J.W., Dunworth, J.N., Awh, M.H., and Bittner, D.F., 1994. Magnetic resonance contrast agents in neuroimaging. New agents and applications. Neuroimaging Clin. N. Am. 4, 175-83.

42. Giesel, F.L., Stroick, M., Griebe, M., Tröster, M., von der Lieth, C.W., Requardt, M., Rius, M., Essig, M., Kauczor, H.U., Hennerici, M.G., and Fatar, M., 2006. Gadofluorine m uptake in stem cells as a new magnetic resonance imaging tracking method: an in vitro and in vivo study. Invest. Radiol. 41, 868-73. 
43. Walczak, P., Kedziorek, D.A., Gilad, A.A., Barnett, B.P., and Bulte, J.W., 2007. Applicability and limitations of MR tracking of neural stem cells with asymmetric cell division and rapid turnover: the case of the shiverer dysmyelinated mouse brain. Magn. Reson. Med. 58, 261-269.

44. Ludemann, L., Wurm, R., and Zimmer, C., 2002. Pharmacokinetic modeling of Gd-DTPA extravasation in brain tumors. Invest. Radiol. 37, 562-570.

45. Hook, M.A., 2013. Animal Models of Spinal Cord Injury, in: Hau J., Schapiro S.J. (Eds.), Handbook of Laboratory Animal Science, CRC Press, pp. 1-42.

46. Friedli, L., Rosenzweig, E.S., Barraud, Q., Schubert, M., Dominici, N., Awai, L., Nielson, J.L., Musienko, P., Nout-Lomas, Y., Zhong, H., Zdunowski, S., Roy, R.R., Strand, S.C., van den Brand, R., Havton, L.A., Beattie, M.S., Bresnahan, J.C., Bézard, E., Bloch, J., Edgerton, V.R., Ferguson, A.R., Curt, A., Tuszynski, M.H., and Courtine, G., 2015. Pronounced species divergence in corticospinal tract reorganization and functional recovery after lateralized spinal cord injury favors primates. Sci Transl Med. 7, 302ra134.

47. Zhang, N., Fang, M., Chen, H., Gou, F., and Ding, M., 2014. Evaluation of spinal cord injury animal models. Neural. Regen. Res. 9, 2008-12.

48. De Vocht, N., Praet, J., Reekmans, K., Le Blon, D., Hoornaert, C., Daans, J., Berneman, Z., Van der Linden, A., and Ponsaerts, P., 2013. Tackling the physiological barriers for successful mesenchymal stem cell transplantation into the central nervous system. Stem Cell Res Ther. 4, 101.

49. Miyanji, F., Furlan, J.C., Aarabi, B., Arnold, P.M., and Fehlings, M.G., 2007. Acute cervical traumatic spinal cord injury: MR imaging findings correlated with neurologic outcome-prospective study with 100 consecutive patients. Radiology. 243, 820-827. 
50. Walczak, P., and Bulte, J.W., 2007. The role of noninvasive cellular imaging in developing cell-based therapies for neurodegenerative disorders. Neurodegener. Dis. 4, 306-313.

\section{Figure legends}

Fig. 1. Efficiency of the positive Gadoteridol-based labeling of MSCs by hypo-osmotic technique. (A) Diagram of the labeling procedure based on the hypo-osmotic shock. (B) Structure of Gadoteridol (Gd-HPDO3A). (C) Number of internalized Gadolinium ions $\left(\mathrm{Gd}^{3+}\right)$ per cell immediately (day 0) and several days after labeling of MSCs. (D) Gd concentration in the supernatants of equivalent number of cells cultured for several days after labeling. (E) MRI T Contrast Enhancement calculated on $\mathrm{T}_{1 \mathrm{w}}$-images of labeled cell pellets. The significance of data in $(\mathbf{C}),(\mathbf{D})$ and $(\mathbf{E})$ is indicated (repeated measures one-way ANOVA test for Fig. 1C and $\mathbf{D}, t$ test for Fig. 1E). (F) Representative $T_{1 \mathrm{w}}-\mathrm{MRI}$ of the pellets of cells incubated with iso-osmotic PBS (1), hypo-osmotic PBS (2), iso-osmotic Gadoteridol solution (100 mM, $300 \mathrm{mOsm} \mathrm{l}^{-1}$ ) (3) and hypo-osmotic Gadoteridol solution (100 mM, $\left.160 \mathrm{mOsm} \mathrm{l}^{-1}\right)$ (4).

Fig. 2. Cell biologic profile after labeling. Cell viability and proliferation rate of MSCs after incubation into iso or hypo-osmotic PBS (Iso and Hypo-PBS-MSCs), and iso- or hypo-osmotic Gadoteridol labeling solution (Iso- and Hypo-Gd-MSCs) evaluated by Trypan Blue exclusion test (A and B). Resealing time of the cell membrane (C), surface marker expression (D) and differentiation potential (E) of unlabeled, Iso- or Hypo-MSCs (Scale bars $=50,100,200$ and $500 \mu \mathrm{m}$ for the $40,20,10$ and $4 \times$ magnifications respectively). Staining for adipocytes and osteocytes was obtained with Oil Red O and Alizarin Red, respectively. See also Figure S1, S2, S3 and S4. 
Fig. 3. In vivo imaging of the cell graft. (A) Percentage enhancement of the SNR calculated on the region of cell transplantation in sagittal $\mathrm{T}_{1 \mathrm{w}}$-images of the spinal cord, acquired $24 \mathrm{~h}$ after the transplantation of 1.5 (left) and $3.0 \times 10^{5}$ (right) Iso-MSCs or Hypo-MSCs. Control experiments were performed by injecting an equivalent volume of saline (Sham Operated animals, SO). The (two-way ANOVA) significance of data is indicated. (B) Representative sagittal $\mathrm{T}_{1 \mathrm{w}}$-imaging (original images in Grayscale, and pseudo-colorized images in 16-colors Lookup Table,) of the cell grafts in Iso-MSC (top), Hypo-MSC (middle), and SO mice (bottom). White arrows indicate the transplantation site. Scale and calibration bars are shown. See also Figure S5 and S6.

Fig. 4. In vivo MRI tracking of MSC migration. (A) Diagram of the imaging protocol: axial images (corresponding to a slice thickness of $1 \mathrm{~mm}$ ) were acquired by positioning slice 0 on the transplantation site and slice 3 (marked by a red asterisk) on the hemisection site. The percentage enhancement of the SNR was calculated on the different axial $\mathrm{T}_{1 \mathrm{w}}$-images acquired at 1 (B), 3 (C), 5 (D), 7 (E), and 10 (F) days after transplantation of Iso-MSCs or Hypo-MSCs. (G) $\mathrm{T}_{1}$ values extracted by $T_{1}$ MR measurements in ROIs drawn on sagittal images at several timepoints after the Hypo-MSC transplantation. ROIs corresponded to axial $\mathrm{T}_{1 \mathrm{w}}$-images reported in the previous experiment. (H) Amount of $\mathrm{Gd}^{3+}$ in the regions of the spinal cord containing the lesion site, the transplantation site, or in the control caudal region, at day 1, 7, or 10 after HypoMSC transplantation. The significance of data is indicated (repeated measures one-way ANOVA in (B-G), and two-way ANOVA in (H)).See also Figure S5 and S7. 
Fig. 5. Representative axial $T_{1 w}$-images showing MSC migration in the spinal cord after the transplantation. Representative axial $\mathrm{T}_{1 \mathrm{w}}$-images ( $7 \times$ magnification) of the spinal cord, showing the positive contrast generated by Iso- or Hypo-MSCs in the lesion site, in the injection site, or in the control caudal region at day 1, 7 or 10 after transplantation. Scale and calibration bars are shown. Originally acquired images are provided in the Supplementary Materials (Figure S8).

Fig. 6. Therapeutic effect. Behavioural tests performed on animals after the transplantation of Iso-MSCs and Hypo-MSCs, or SO mice. The performed motor tests were: the BMS (A), the foot-fault (B), the PaGE (C) and the hindlimb flexion (D) tests. The motor evaluation was pursued over a time range of 40 days after transplantation, and the (repeated measures one-way ANOVA) significance of the data collected on the last monitoring day is indicated.

Fig. 7. Characterization of the migratory stream. Spinal cord MRI and cell microscopy of a representative mouse sacrificed 7 days after transplantation with Hypo-MSCs. (A) Original or pseudo-colorized coronal $\mathrm{T}_{2 \mathrm{w}}$ and $\mathrm{T}_{1 \mathrm{w}}$-MRI of the spinal cord (LT, Lookup Table in pseudocolorized images). White arrows indicate the lesion and transplantation sites (in rostral and caudal direction, respectively). (B) Hypo-GFP ${ }^{+}$MSCs distributed in a continuous stream between the graft site and the hemisection site. (C-D) IBA1 and (E-F) GFAP immunofluorescence showing the microgliosis and astrogliosis, both at the lesion and transplantation sites. (G-I) Distribution and morphology of Hypo-GFP ${ }^{+} \mathrm{MSC}$ in the migratory stream. (J-M) Immunofluorescence for SMI32 (in red), highlighting the distribution of $\mathrm{GFP}^{+}$ Hypo-MSCs along white matter fibers. Scale bar $=1 \mathrm{~mm}$ in A, $500 \mu \mathrm{m}$ in B, $50 \mu \mathrm{m}$ in C-D-E-FH-I, and $25 \mu \mathrm{m}$ in G-J-L-L-M. 

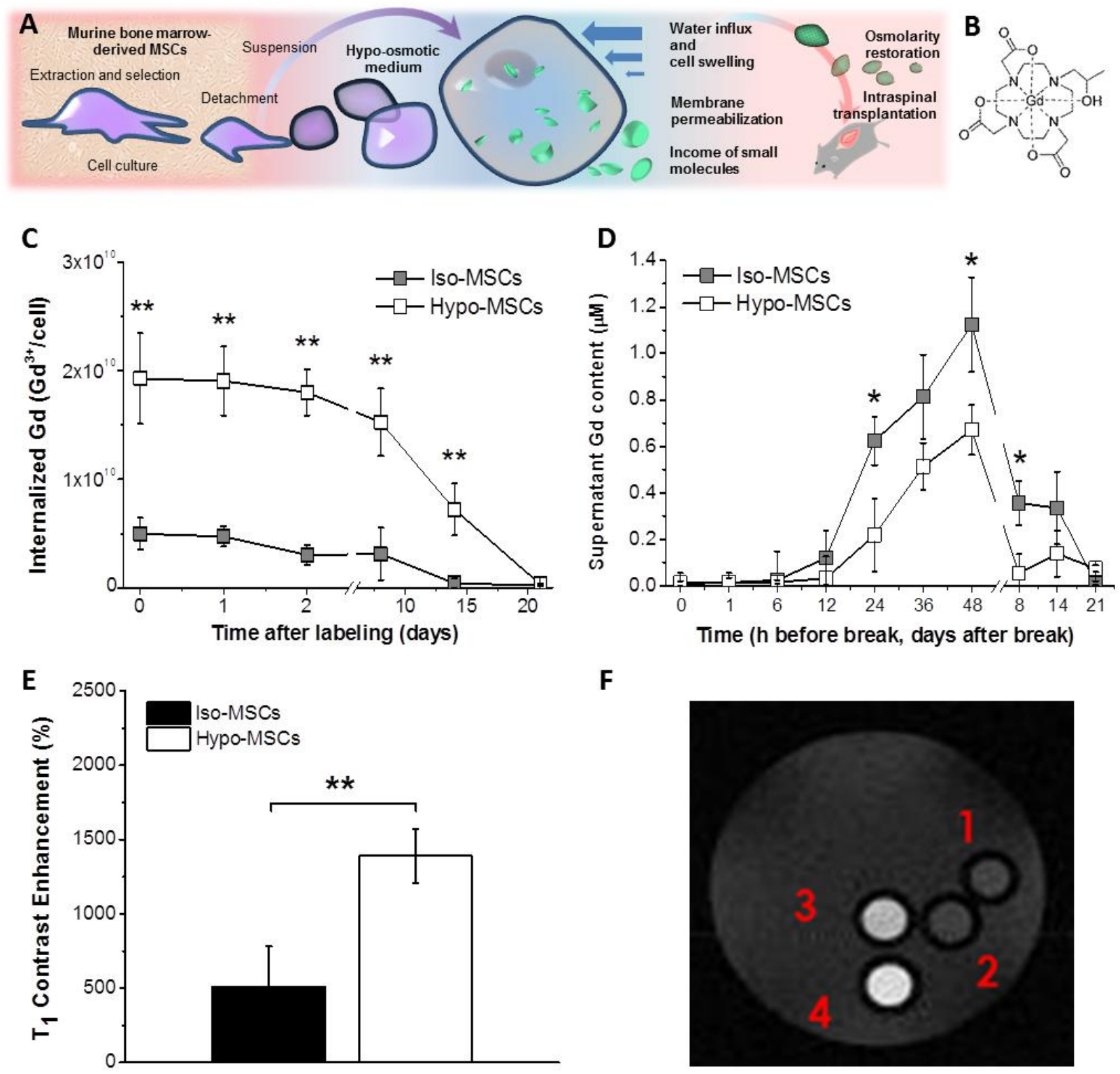

\section{F}

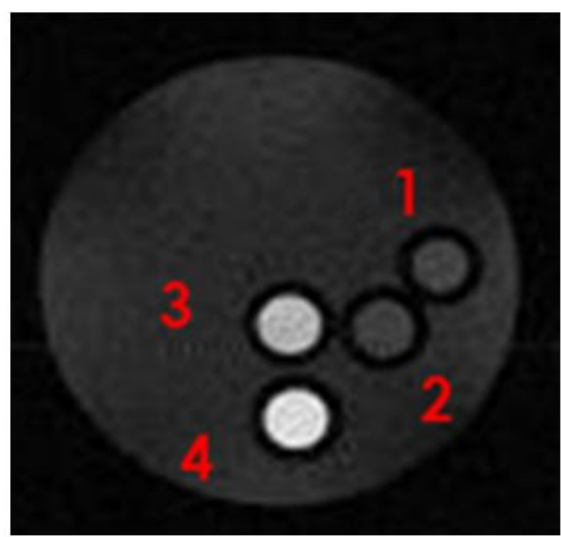

\section{Figure 1}


A

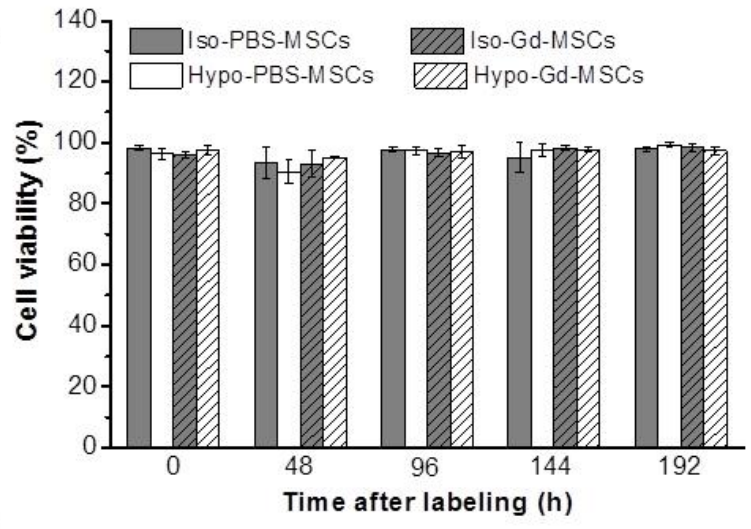

C

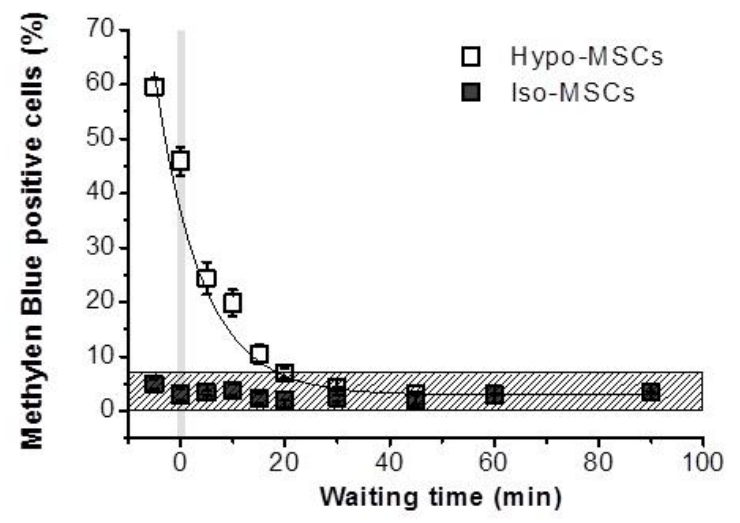

B

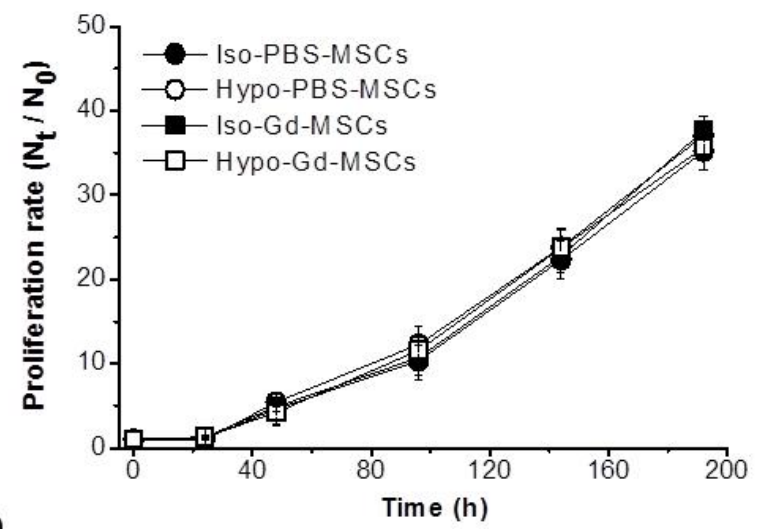

D

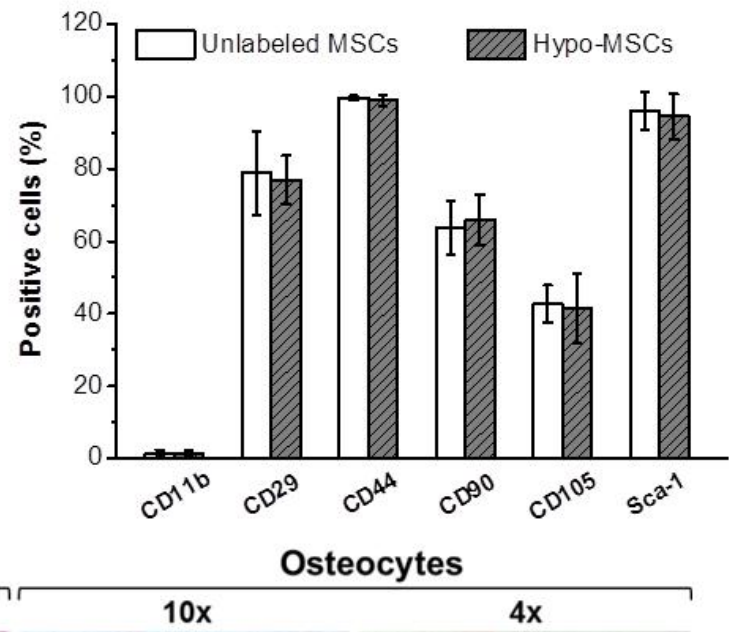

E

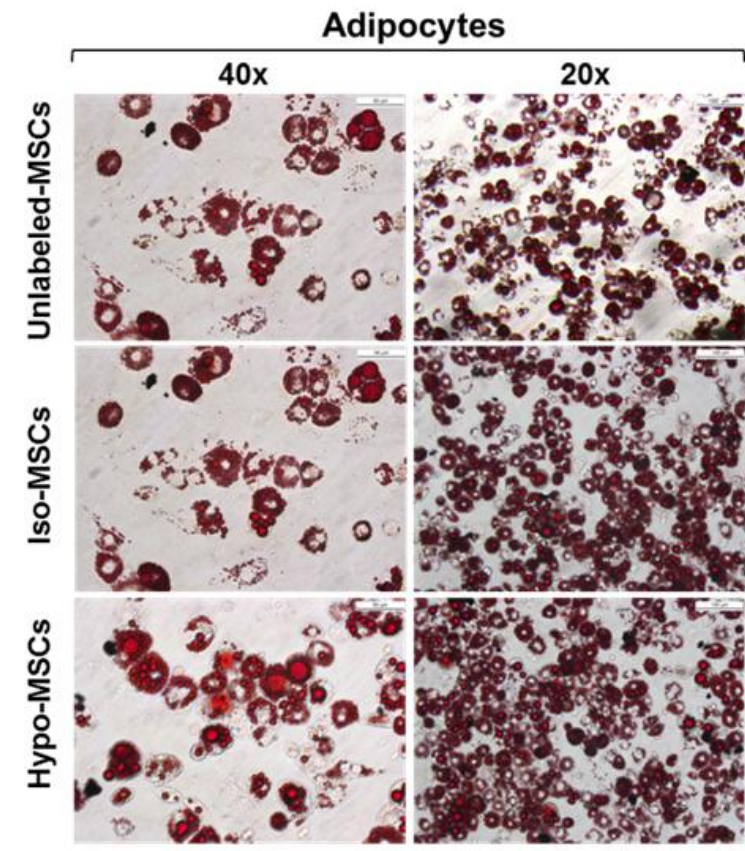

Figure 2 


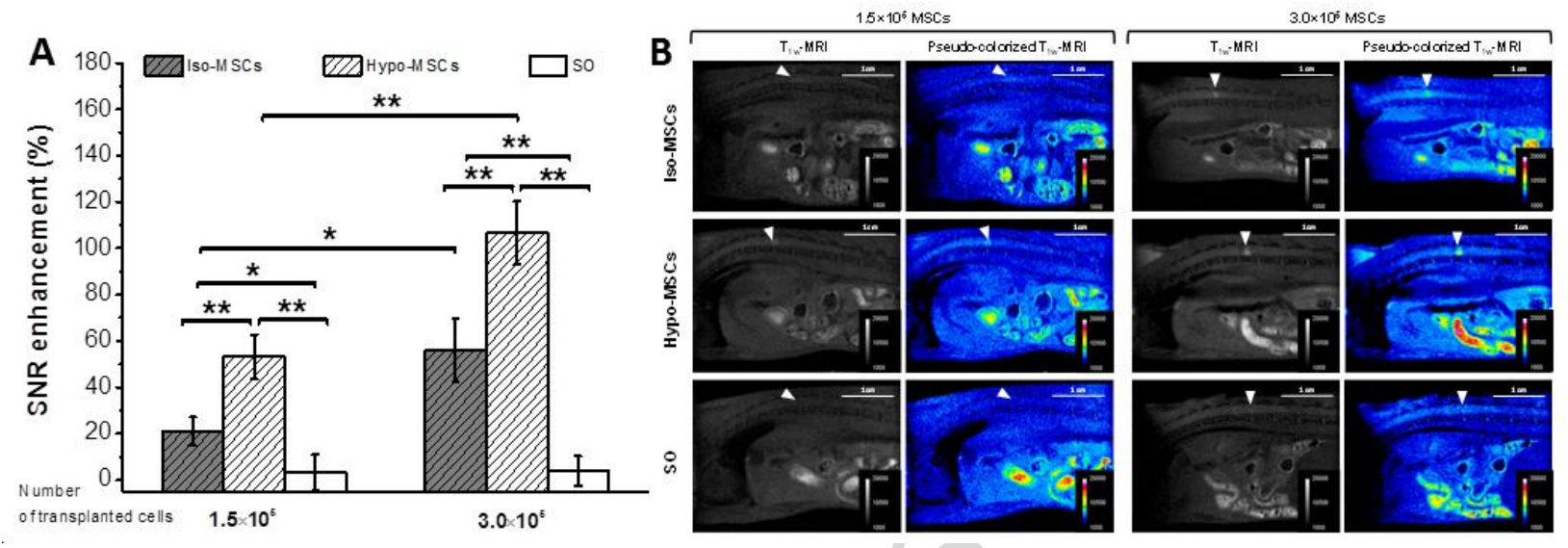

Figure 3 

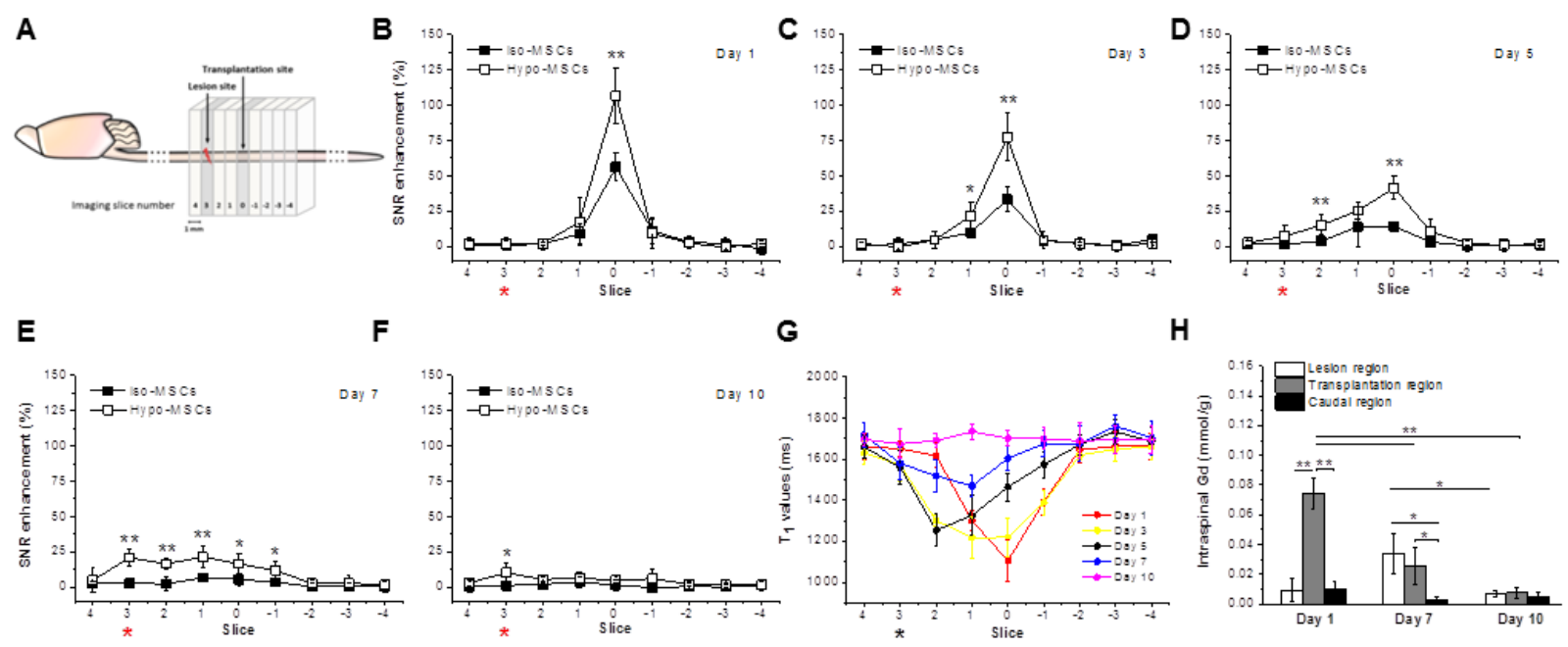

$\mathbf{F}$

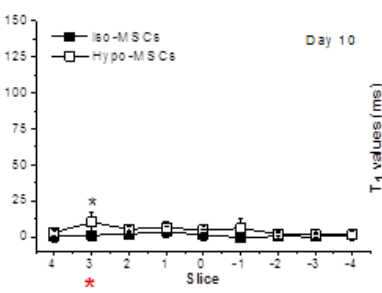

G

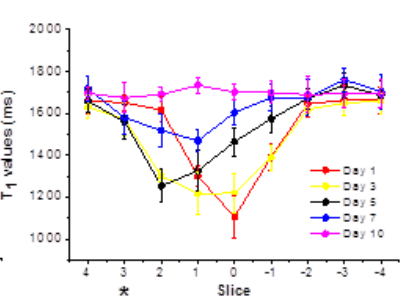

H

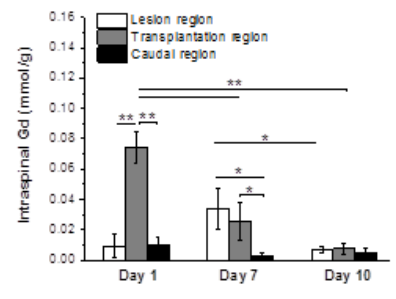

Figure 4 


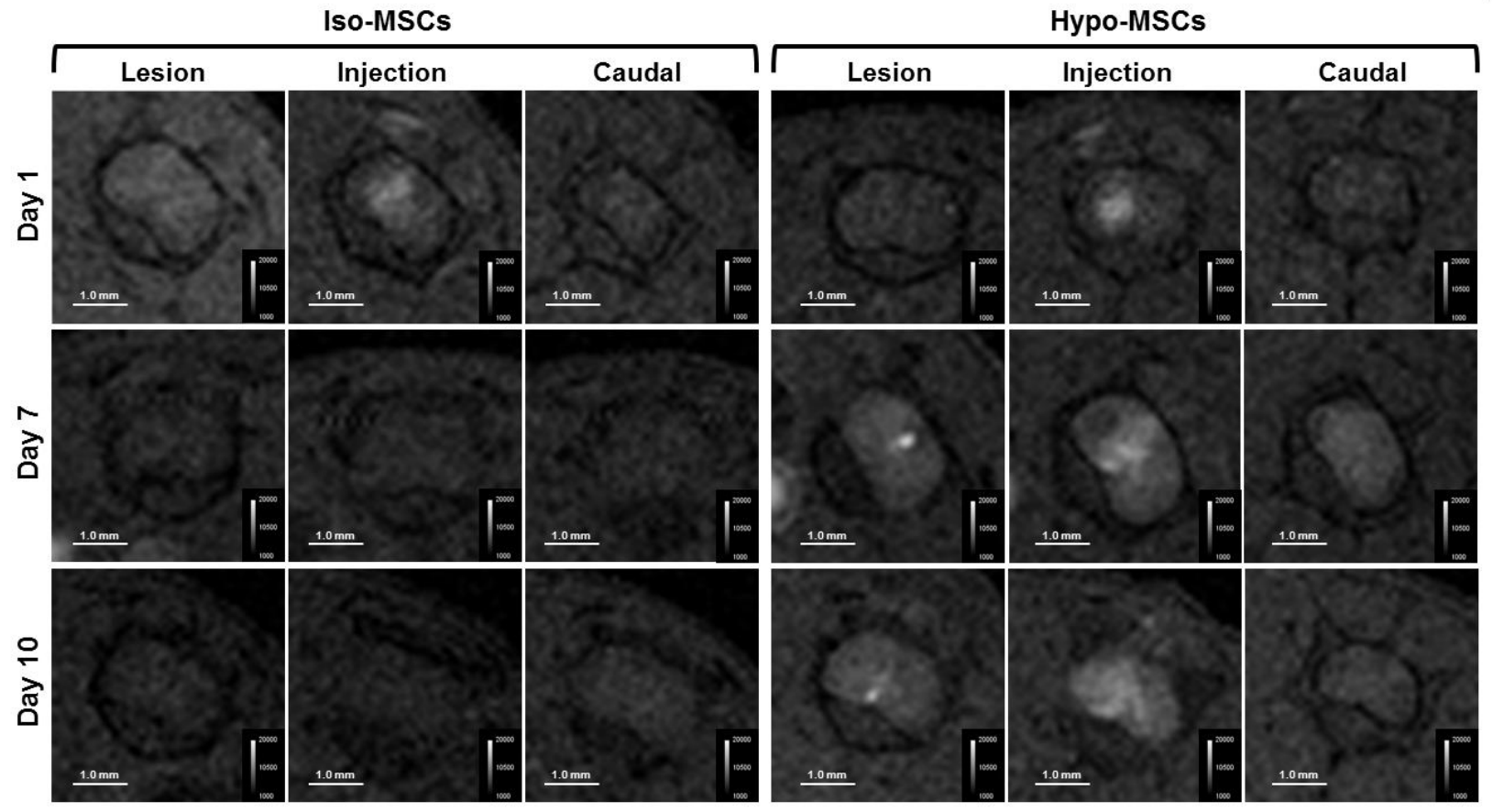

Figure 5 

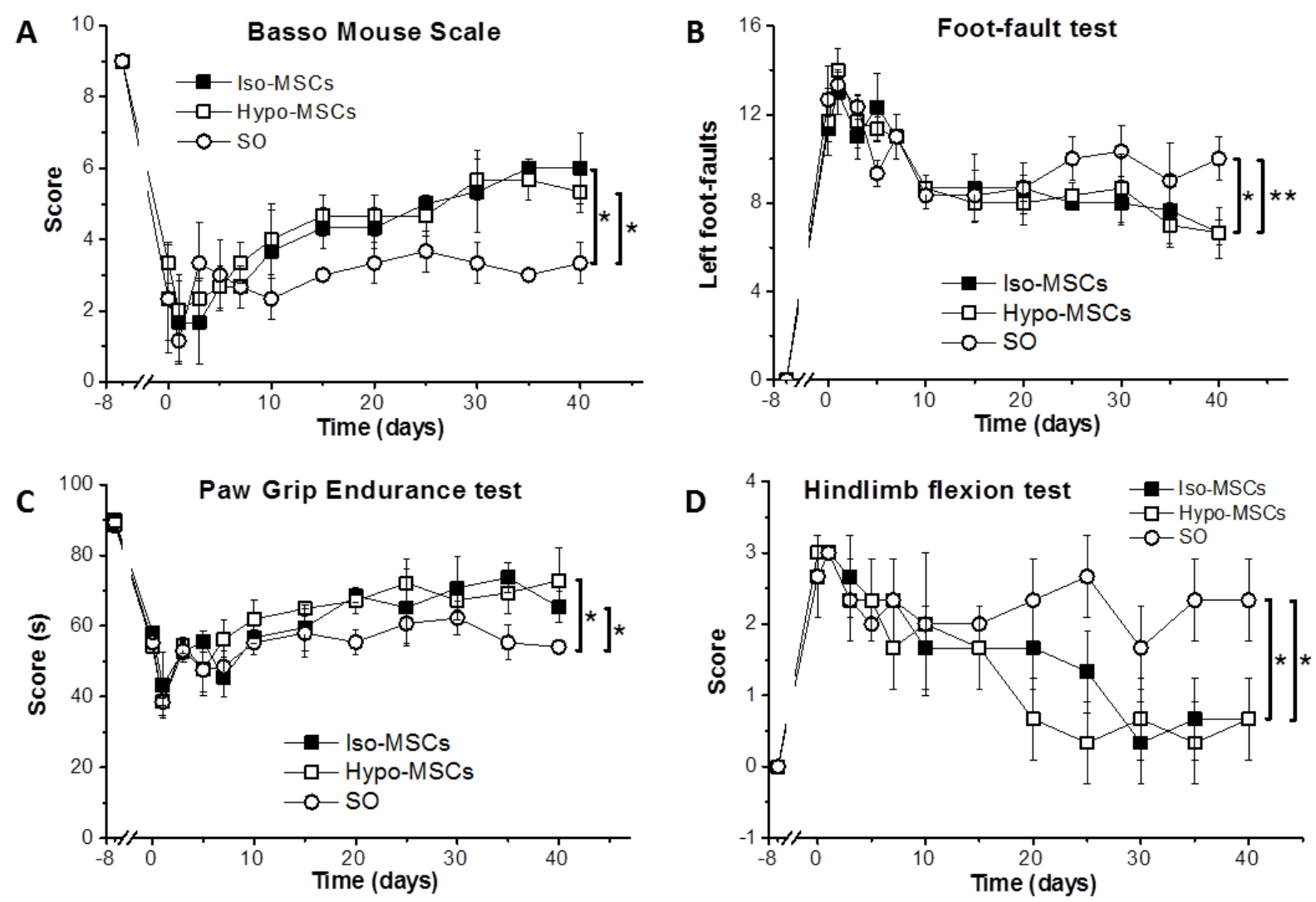

Figure 6 


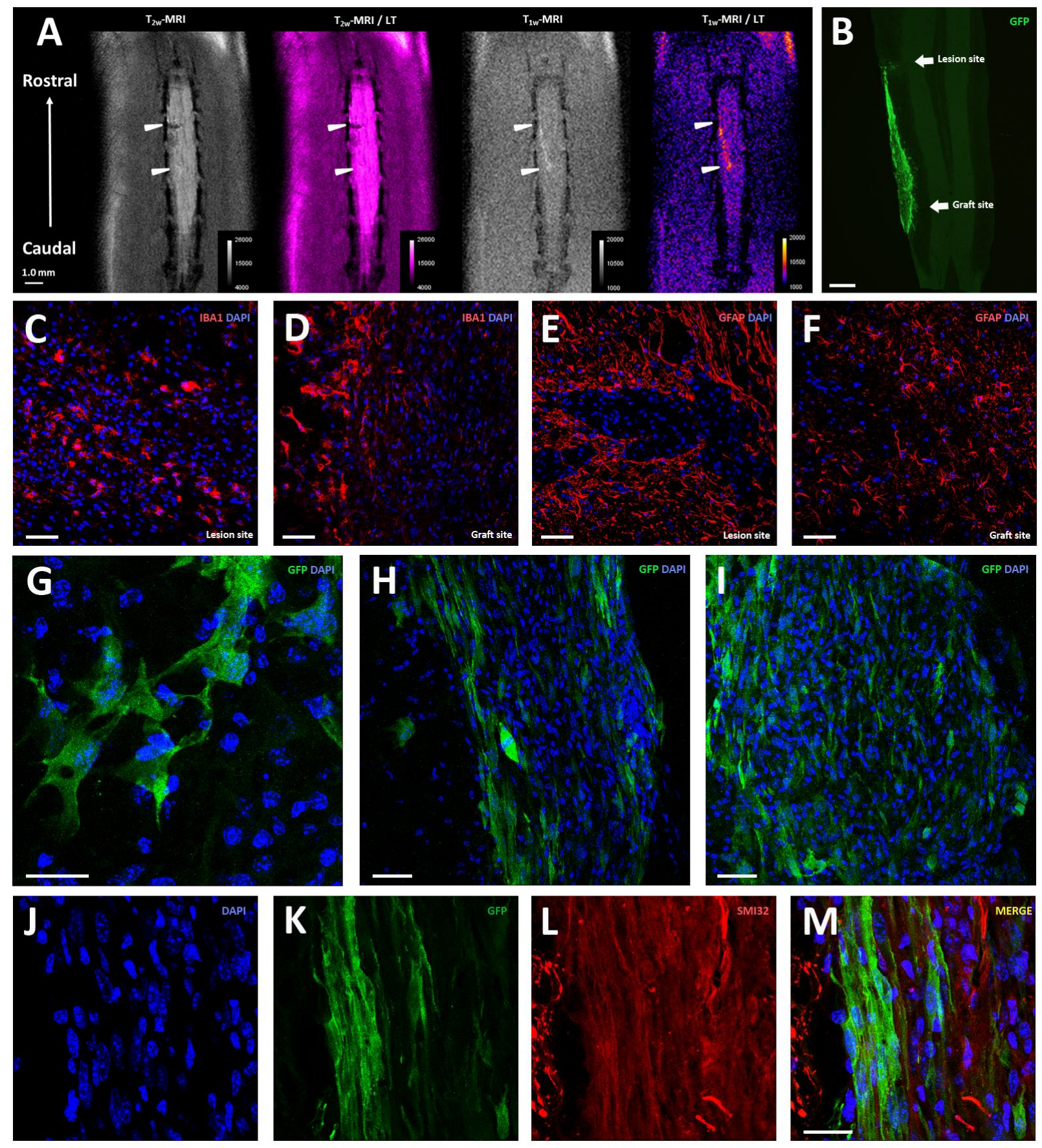

Figure 7 


\section{Highlights}

Compared to isotonic incubations, the hypo-osmotic labeling enhances the MRI of cells

The hypo-osmolarity significantly supports the agent uptake and contrast generation

The MSC-transplantation imaging in SCI mice is improved by simple labeling expedients

The migration of $3.0 \times 10^{5}$ labeled MSCs is reliably tracked in vivo for 10 days

The biological profile and therapeutic effect of labeled MSCs are preserved 